\title{
Chondrocyte Behavior on Micropatterns Fabricated Using Layer-by-Layer Lift-Off: Morphological Analysis
}

\author{
Jameel Shaik, ${ }^{1,2,3}$ Javeed Shaikh Mohammed, ${ }^{1,4}$ \\ Michael J. McShane, ${ }^{1,2,5}$ and David K. Mills ${ }^{1,2,6}$ \\ ${ }^{1}$ Institute for Micromanufacturing, Louisiana Tech University, Ruston, LA 71272, USA \\ ${ }^{2}$ Biomedical Engineering Program, Louisiana Tech University, Ruston, LA 71272, USA \\ ${ }^{3}$ School of Bio Sciences \& Technology, VIT University, Vellore 632014, India \\ ${ }^{4}$ Biomedical Technology Department, King Saud University, Riyadh 11433, Saudi Arabia \\ ${ }^{5}$ Biomedical Engineering Program, Texas A\&M University, College Station, TX 77843, USA \\ ${ }^{6}$ School of Biological Sciences, Louisiana Tech University, Ruston, LA 71272, USA
}

Correspondence should be addressed to David K. Mills; dkmills@latech.edu

Received 16 February 2013; Revised 24 April 2013; Accepted 25 April 2013

Academic Editor: Rad Zdero

Copyright (C) 2013 Jameel Shaik et al. This is an open access article distributed under the Creative Commons Attribution License, which permits unrestricted use, distribution, and reproduction in any medium, provided the original work is properly cited.

Cell patterning has emerged as an elegant tool in developing cellular arrays, bioreactors, biosensors, and lab-on-chip devices and for use in engineering neotissue for repair or regeneration. In this study, micropatterned surfaces were created using the layer-by-layer lift-off (LbL-LO) method for analyzing canine chondrocytes response to patterned substrates. Five materials were chosen based on our previous studies. These included: poly(dimethyldiallylammonium chloride) (PDDA), poly(ethyleneimine) (PEI), poly(styrene sulfonate) (PSS), collagen, and chondroitin sulfate (CS). The substrates were patterned with these five different materials, in five and ten bilayers, resulting in the following multilayer nanofilm architectures: (PSS/PDDA $)_{5},(\mathrm{PSS} / \mathrm{PDDA})_{10}$; $(\mathrm{CS} / \mathrm{PEI})_{4} / \mathrm{CS}$, $(\mathrm{CS} / \mathrm{PEI})_{9} / \mathrm{CS} ;(\mathrm{PSS} / \mathrm{PEI})_{5},(\mathrm{PSS} / \mathrm{PEI})_{10} ;(\mathrm{PSS} / \text { Collagen })_{5},(\mathrm{PSS} / \mathrm{Collagen})_{10} ;(\mathrm{PSS} / \mathrm{PEI})_{4} / \mathrm{PSS},(\mathrm{PSS} / \mathrm{PEI})_{9} / \mathrm{PSS}$. Cell characterization studies were used to assess the viability, longevity, and cellular response to the configured patterned multilayer architectures. The cumulative cell characterization data suggests that cell viability, longevity, and functionality were enhanced on micropatterned PEI, PSS, collagen, and CS multilayer nanofilms suggesting their possible use in biomedical applications.

\section{Introduction}

Replicating the highly structured in vivo microenvironment is crucial in understanding cellular behavior [1]. Traditional cell culture surfaces cannot provide sufficient control over the cellular microenvironment [2] for use in studying many anchorage-dependent cellular processes such as cellular differentiation, proliferation, and phenotypic expression. Cell supportive substrates, with the requisite spatiotemporal surface properties, are also a critical feature in designing appropriate biomaterial surfaces for use in cell arrays, bioreactors, biosensors [3], and cocultures [4-6] and for use in engineering new tissues for repair or replacement.

Micropatterned surfaces have been explored as a means not only to answer fundamental questions in cell biology but also to develop cell culture substrates with surface features tailored for specific bio- and tissue engineering applications $[2,3,7]$. This was demonstrated by the growth of hepatocytes on micropatterned surfaces $[4,5]$. The authors observed decreased DNA production and increased cellular apoptosis associated with a decrease in the adhesiveness of the surfaces [7]. Cell shape was also found to be the regulatory factor in both cell apoptosis and growth $[7,8]$. This was achieved by an increasing restriction of the size of micropatterned islands coated with different densities of ECM and growing bovine and human endothelial cells on these islands [2].

Patterning cells using cell-adhesive [9-13] or cellrepulsive [14-20] surfaces or combinations [21,22] of adhesive and nonadhesive surfaces have been developed, and a wide variety of eukaryotic cells have been grown and studied on these micropatterned surfaces $[2,5,8,20,23-25]$. 
A broad range of materials have been used in creating these micropatterned cell culture surfaces $[3,8,26,27]$.

Micropatterned substrates have also lent credence to the important understanding that the degree of cellular contraction is crucial in determining a cells fate during differentiation, especially in the case of stem cells [1]. This has been demonstrated in several studies that showed that variation in micropattern size directed stem cell differentiation into different cell lineages. For example, human mesenchymal stem cells (hMSCs) cultured in differentiating medium exhibited differences in the contraction levels and also exhibited different lineages-those hMSCs grown on $1,000 \mu \mathrm{m}^{2}$ micropatterns had low contraction levels and differentiated into adipocytes, while hMSCs plated on $10,000 \mu \mathrm{m}^{2}$ micropatterns were highly contracted and differentiated into osteoblasts [28]. Similarly, hMSCs treated with transforming growth factor $\beta$ (TGF- $\beta$ ) exhibited differential behavior dependent upon the size of micropatterns-hMSCs plated on small micropatterns differentiated into chondrocytes, while hMSCs plated on large micropatterns differentiated into myocytes [29].

The use of layer by layer (LbL) nanoassembly for creating micropatterned surfaces brings in all the advantages offered by LbL-simplicity and excellent control over surface properties such as thickness, roughness, and porosity [3]. LbL surfaces can potentially be used in obtaining the precise cellular microenvironment as the surfaces can be tuned to release the factors necessary for the growth and regulation of cells [22]. Polyelectrolytes and proteins deposited through the LbL technique can be used to create either cell-resistant or cell-adhesive micropatterns. Our previous studies focused on the growth and behavior of bovine articular chondrocytes [30], human chondrosarcoma cells, and canine chondrocytes [31] on LbL-assembled nanothin films of varying configurations. We chose chondrocytes as our model cell type as they have a very plastic phenotype. Cell characterization studies were used to assess chondrocyte viability, longevity, and functionality in response to the configured architectures. Cell adhesion, shape, and functionality are linked to the nature of the underlying culture substrate $[32,33]$.

Our goal in this study was to expand our previous work by examining interspecies differences in chondrocyte behavior on micropatterned substrates created using the LbL-LO method. Our expectation was that difference in nanofilm architectures atop micropatterned substrates would evoke variations in chondrocyte behavior. Different micropatterned surfaces were created using the LbLLO technique $[6,34-36]$. Based on our previous studies, five polyelectrolytes/proteins were used to construct the nanofilms [31]. These were poly(dimethyldiallylammonium chloride) (PDDA), poly(ethyleneimine) (PEI), poly(styrene sulfonate) (PSS), collagen, and chondroitin sulfate (CS). The substrates were patterned, in five and ten bilayers, resulting in the following multilayer nanofilm architectures: $(\mathrm{PSS} / \mathrm{PDDA})_{5},(\mathrm{PSS} / \mathrm{PDDA})_{10} ;(\mathrm{CS} / \mathrm{PEI})_{4} / \mathrm{CS},(\mathrm{CS} / \mathrm{PEI})_{9} / \mathrm{CS}$; $(\mathrm{PSS} / \mathrm{PEI})_{5},(\mathrm{PSS} / \mathrm{PEI})_{10}$; (PSS/Collagen $)_{5},(\mathrm{PSS} / \text { Collagen })_{10}$; $(\mathrm{PSS} / \mathrm{PEI})_{4} / \mathrm{PSS},(\mathrm{PSS} / \mathrm{PEI})_{9} / \mathrm{PSS}$.

\section{Materials and Methods}

2.1. Substrates. Microscope cover slips (Thickness number 2, $18 \times 18 \mathrm{~mm}^{2}$, Electron Microscopy Sciences, Hatfield, PA, USA) were used as the substrates for deposition of the micropatterns. These substrates were chosen for ease in optical characterization.

\subsection{Chemicals. Nano-Strip from CYANTEK Corporation} (Fremont, CA); positive photoresist S1813 and positive resist developer MF-319 from the Shipley Corporation (Marlboro, Massachusetts) were used. All the chemicals were purchased from Sigma-Aldrich unless otherwise specified. All commercial chemicals were used following manufacturer's directions.

2.3. Preparation of Polyelectrolyte, Polypeptide, and Protein Solutions. PDDA (Mw $\sim 150 \mathrm{kDa})$, PSS $(\mathrm{Mw} \sim 1 \mathrm{MDa})$ solutions were prepared at concentrations of $2 \mathrm{mg} \mathrm{mL}^{-1}$ with $0.5 \mathrm{M} \mathrm{KCl}$, and a PEI $(\mathrm{Mw} \sim 750 \mathrm{kDa})$ solution of $2 \mathrm{mg} \mathrm{mL}^{-1}$ was prepared in deionized (DI) $\mathrm{H}_{2} \mathrm{O}$ for use in $\mathrm{LbL}$ nanoassembly. Chondroitin sulfate $(\mathrm{Mw} \sim 500 \mathrm{Da})$ and type I collagen (Mw $\sim 100 \mathrm{kDa}$ ) (Cohesion, Palo Alto, CA, USA) were prepared at a concentration of $120 \mu \mathrm{g} \mathrm{mL}^{-1}$. All solutions were prepared using DI water with a resistivity of $18.2 \mathrm{M} \Omega \mathrm{cm}$ (Millipore systems, Burlington, MA, USA).

2.4. Substrate Pretreatment. The substrates were first incubated in Nano-Strip at $70^{\circ} \mathrm{C}$ for $1 \mathrm{~h}$ followed by rinsing in DI water anddried in a $\mathrm{N}_{2}$ stream to remove any organic materials and to create a uniform negative charge on the substrates. A precursor layer of PDDA was then deposited onto the substrates to render a cytophobic background on the substrates. This was based on our previous results with smooth muscle and neuronal cells [35, 37]. PDDA application is not exclusive as any cytophobic material other than PDDA can also be used.

2.5. Photolithography. To help withstand the centrifugal forces during spin coating, the PDDA-coated glass substrates were attached to silicon wafer pieces using photoresist S1813 and heated at $165^{\circ} \mathrm{C}$ for $5 \mathrm{~min}$ to hard bake the photoresist. Next, positive photoresist S1813 was spun (1000 rpm$100 \mathrm{r} \mathrm{s}^{-1}-10 \mathrm{~s}, 3000 \mathrm{rpm}-500 \mathrm{r} \mathrm{s}^{-1}-50 \mathrm{~s}$ ) on the PDDA-coated substrates, soft baked at $115^{\circ} \mathrm{C}$ for $1 \mathrm{~min}$, and photo-patterned using UV radiation $\left(400 \mathrm{~nm}, 7 \mathrm{~mW} \mathrm{~cm}^{-2}\right)$ applied for $18 \mathrm{~s}$. The mask used for pattern transfer contained $80 \mu \mathrm{m}$ wide stripe patterns separated by $240 \mu \mathrm{m}$ and $100 \mu \mathrm{m}$ wide stripe patterns separated by $300 \mu \mathrm{m}$. Finally, the patterns were developed for $15 \mathrm{~s}$ using MF-319, and the substrates quickly rinsed in DI water and dried using $\mathrm{N}_{2}$.

2.6. Layer-by-Layer (LbL) Self-Assembly. Micropatterned substrates were then modified using LbL nanoassembly. The substrates were dipped in polyelectrolyte and protein solutions for $10 \mathrm{~min}$ and $30 \mathrm{~min}$, respectively. PSS or PEI was 


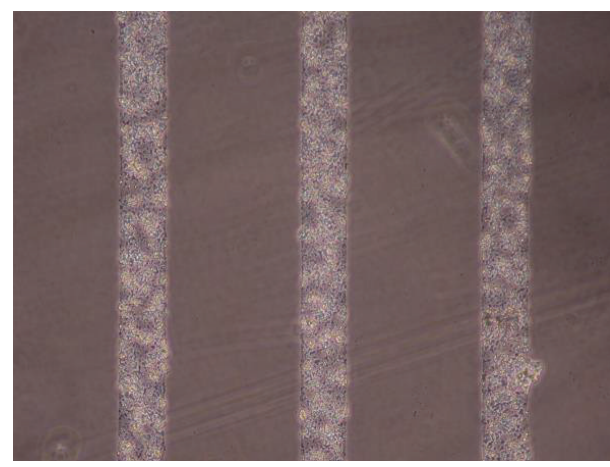

(a)

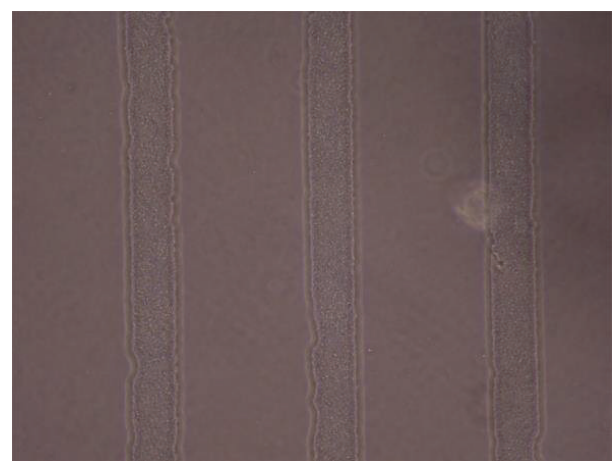

(c)

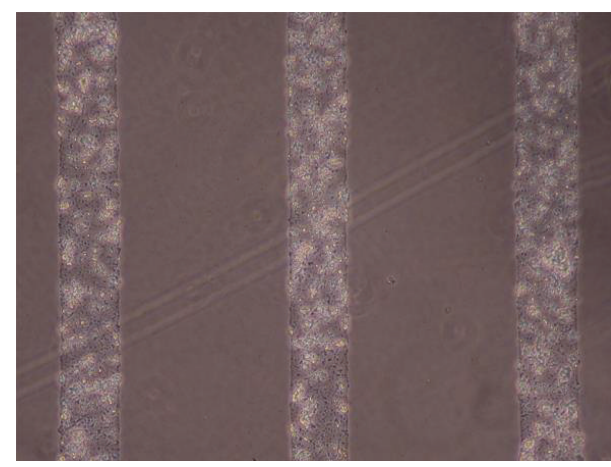

(b)

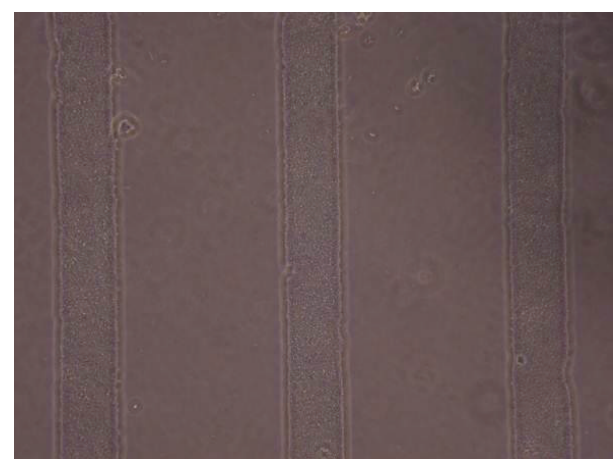

(d)

Figure 1: Micropatterned substrates with PDDA as the outermost layer: (a) (PSS/PDDA) $)_{5}-80 \mu \mathrm{m},(\mathrm{b})(\mathrm{PSS} / \mathrm{PDDA})_{5}-100 \mu \mathrm{m},(\mathrm{c})$ $(\mathrm{PSS} / \mathrm{PDDA})_{10}-80 \mu \mathrm{m}$, and (d) (PSS/PDDA) $)_{10}-100 \mu \mathrm{m}$.

used as the polyanions in all multilayer nanofilm configurations. After every deposition step, substrates were rinsed in DI water and then dried using $\mathrm{N}_{2}$. Substrates were patterned with PDDA, PSS, PEI, collagen, and CS as either five- or tenbilayer nanofilms. Thus, the following configurations were fabricated: (PSS/PDDA $)_{5},(\mathrm{PSS} / \mathrm{PDDA})_{10} ;(\mathrm{CS} / \mathrm{PEI})_{4} / \mathrm{CS}$, $(\mathrm{CS} / \mathrm{PEI})_{9} / \mathrm{CS} ; \quad(\mathrm{PSS} / \mathrm{PEI})_{5},(\mathrm{PSS} / \mathrm{PEI})_{10} ;$ (PSS/Collagen $)_{5}$, (PSS/Collagen $)_{10} ;(\mathrm{PSS} / \mathrm{PEI})_{4} / \mathrm{PSS}$, (PSS/PEI) $)_{9} / \mathrm{PSS}$.

2.7. Lift-Off. Lift-off was performed by sonicating the substrates in acetone for 5 to 10 minutes. The photoresist and the nanofilms deposited on the photoresist were removed during the lift-off process. Also, the cover slip glass was detached from the silicon wafer. Surprisingly, the use of acetone was shown not to affect the biological functions of the molecules used in the LbL-LO process [38].

2.8. Cell Culture. Canine chondrocytes $(\mathrm{CnC})$ were obtained from Cell Applications, Inc. (San Diego, CA, USA). Chondrocytes were isolated from normal canine articular cartilage and obtained at second passage. Their phenotype is preserved through ten population doublings. Chondrocytes were grown as monolayers and maintained in Chondrocyte Growth Medium (Cell Applications, Inc., San Diego, CA, USA) until the necessary cell numbers were obtained. Canine chondrocytes from passage three were used for the cell characterization studies on the micropatterned surfaces.
2.9. Cell Characterization. Phase-contrast microscopy was used to demonstrate the successful creation of the micropatterns. Phase-contrast microscopy was also used for the characterization of $\mathrm{CnC}$ on the micropatterned surfaces.

\section{Results}

3.1. Phase-Contrast Microscopy of Micropatterned Substrates. Figures 1, 2, 3, 4, and 5 contain phase-contrast images of the micropatterned substrates of five different materials, in five and ten-bilayer nanofilm configurations. In all the multilayer nanofilm architectures, the terminating nanofilm layer was one of the five different materials studied here. The images show $80 \mu \mathrm{m}$ wide stripe patterns separated by $240 \mu \mathrm{m}$ or $100 \mu \mathrm{m}$ wide stripe patterns separated by $300 \mu \mathrm{m}$.

All the micropatterns, with the exception of collagen, had high edge resolution. There could be several factors contributing to the low resolution of edges in collagen micropatterns. Some of the factors affecting the edge resolution of the collagen micropatterns could be deposition time of collagen, $\mathrm{pH}$ of collagen solution, sonication time during lift-off, and the height of photoresist used to define the stripe micropatterns in LbL-LO. From Figure 4, it also appears that the $100 \mu \mathrm{m}$ collagen micropatterns have better edge resolution compared to the $80 \mu \mathrm{m}$ micropatterns. One of the reasons for this difference in edge resolution of collagen micropatterns could be due to the differences in the spacing between the stripe micropatterns, which is $240 \mu \mathrm{m}$ for the 


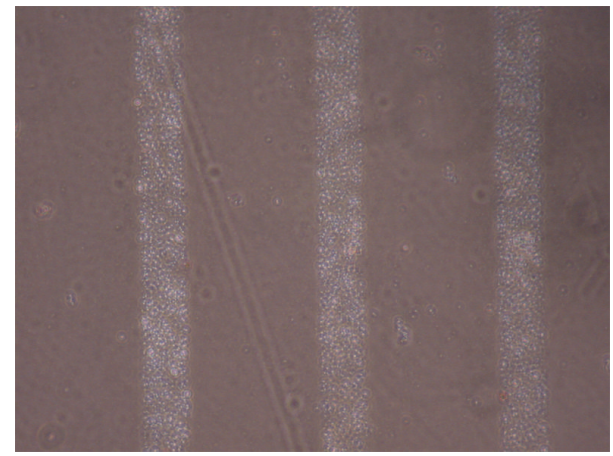

(a)

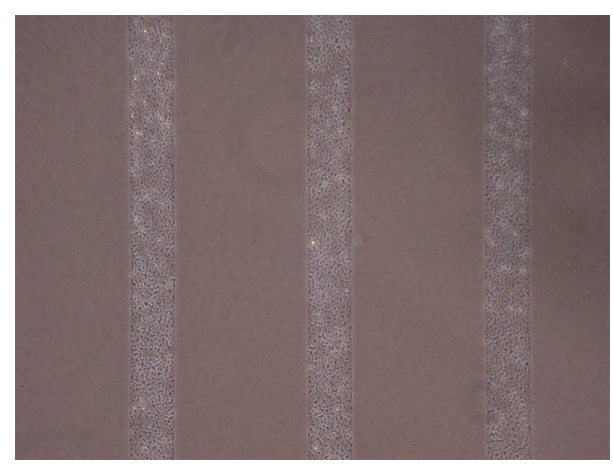

(c)

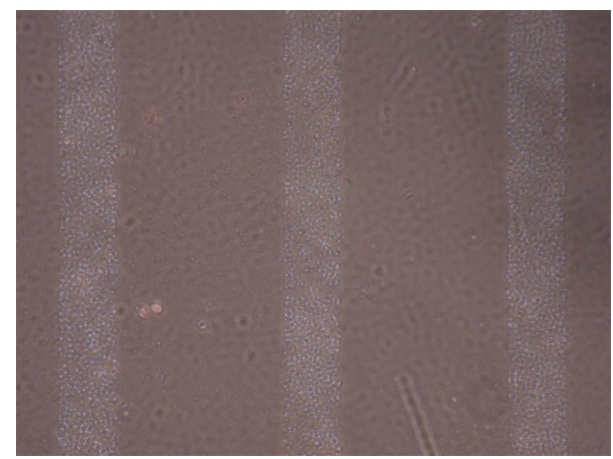

(b)

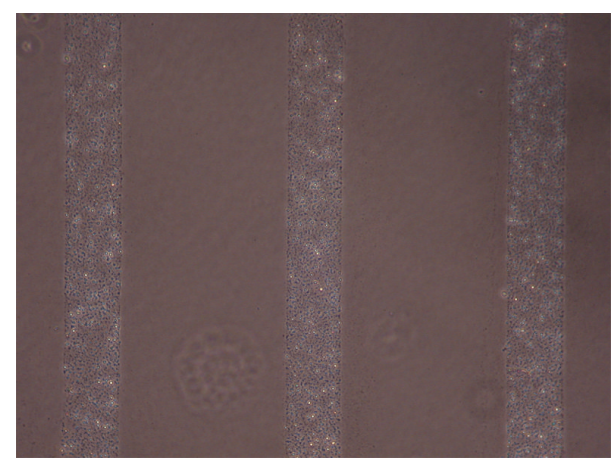

(d)

FIGURE 2: Micropatterned substrates with $\mathrm{CS}$ as the outermost layer: (a) $(\mathrm{CS} / \mathrm{PEI})_{4} / \mathrm{CS}-80 \mu \mathrm{m}, \quad(\mathrm{b})(\mathrm{CS} / \mathrm{PEI})_{4} / \mathrm{CS}-100 \mu \mathrm{m}, \quad(\mathrm{c})$ $(\mathrm{CS} / \mathrm{PEI})_{9} / \mathrm{CS}-80 \mu \mathrm{m}$, and $(\mathrm{d})(\mathrm{CS} / \mathrm{PEI})_{9} / \mathrm{CS}-100 \mu \mathrm{m}$.

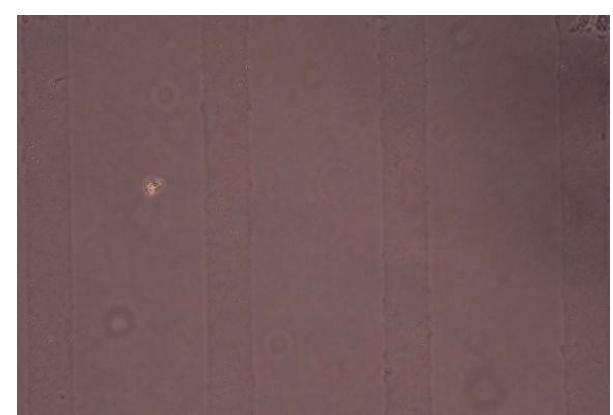

(a)

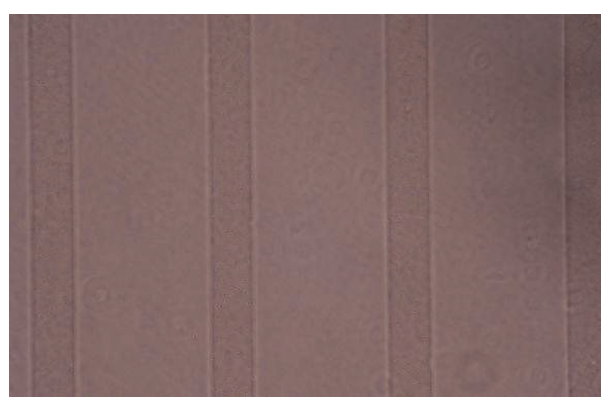

(c)

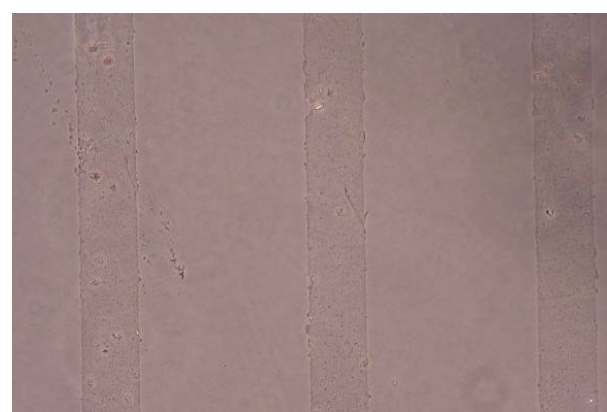

(b)

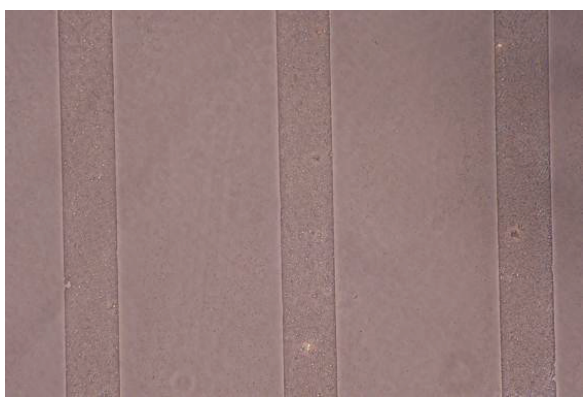

(d)

Figure 3: Micropatterned substrates with PEI as the outermost layer: (a) (PSS/PEI) $)_{5}-80 \mu \mathrm{m}$, (b) (PSS/PEI) $-100 \mu \mathrm{m},(\mathrm{c})(\mathrm{PSS} / \mathrm{PEI})_{10}-$ $80 \mu \mathrm{m}$, and (d) $(\mathrm{PSS} / \mathrm{PEI})_{10}-100 \mu \mathrm{m}$. 


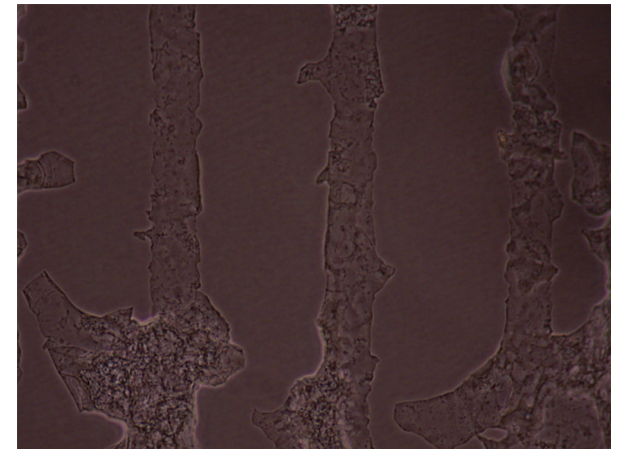

(a)



(c)

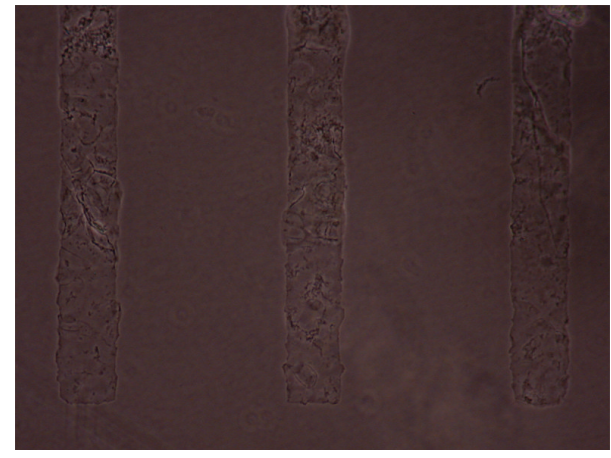

(b)



(d)

FIGURE 4: Micropatterned substrates with collagen as the outermost layer: (a) (PSS/Collagen) $)_{5}-80 \mu \mathrm{m},(\mathrm{b})(\mathrm{PSS} / \mathrm{Collagen})_{5}-100 \mu \mathrm{m},(\mathrm{c})$ (PSS/Collagen) $)_{10}-80 \mu \mathrm{m}$, and (d) (PSS/Collagen) $)_{10}-100 \mu \mathrm{m}$.

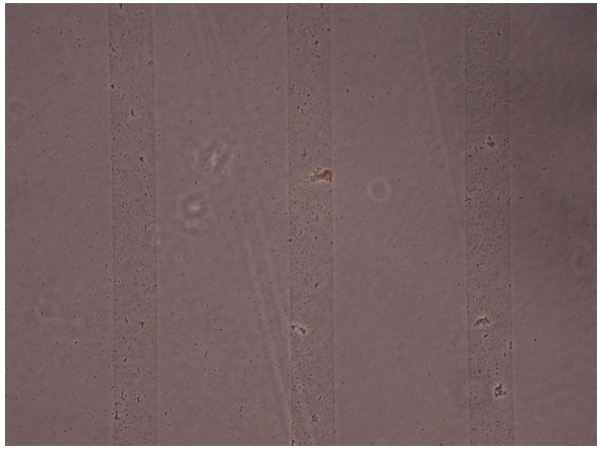

(a)

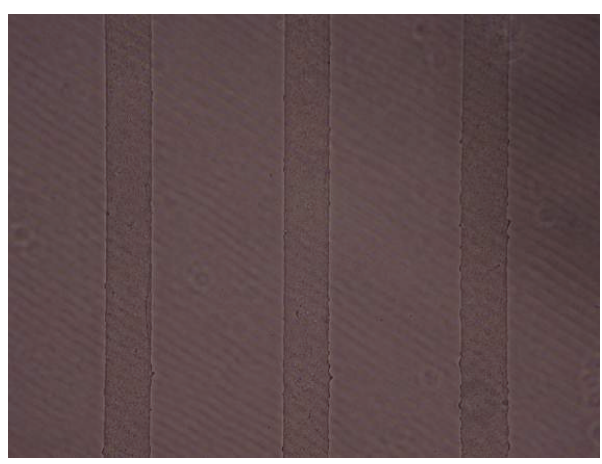

(c)

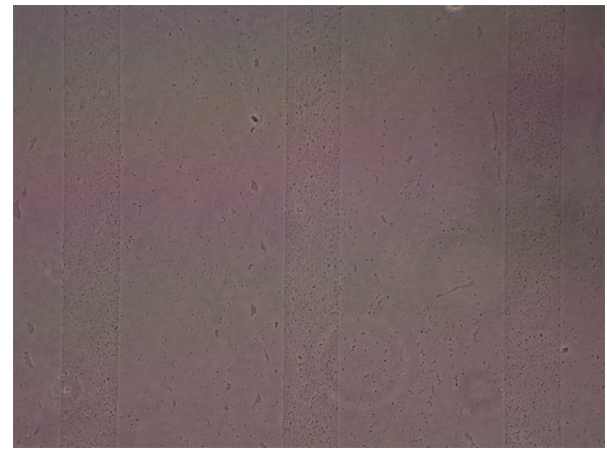

(b)

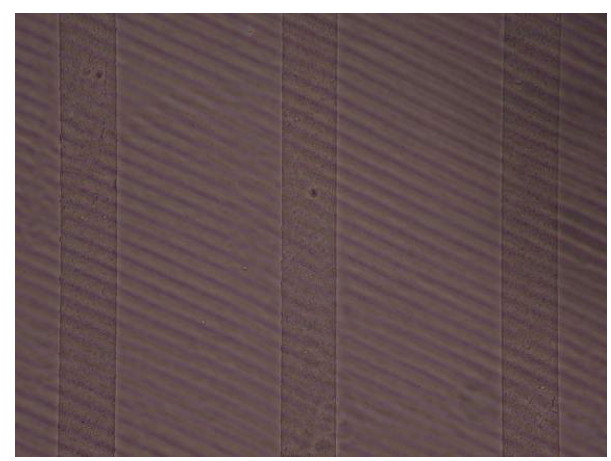

(d)

FIGURE 5: Micropatterned substrates with PSS as the outermost layer: (a) (PSS/PEI) ${ }_{4} / \mathrm{PSS}-80 \mu \mathrm{m}, \quad(\mathrm{b})(\mathrm{PSS} / \mathrm{PEI})_{4} / \mathrm{PSS}-100 \mu \mathrm{m}, \quad(\mathrm{c})$ $(\mathrm{PSS} / \mathrm{PEI})_{9} / \mathrm{PSS}-80 \mu \mathrm{m}$, and $(\mathrm{d})(\mathrm{PSS} / \mathrm{PEI})_{9} / \mathrm{PSS}-100 \mu \mathrm{m}$. 




(a)

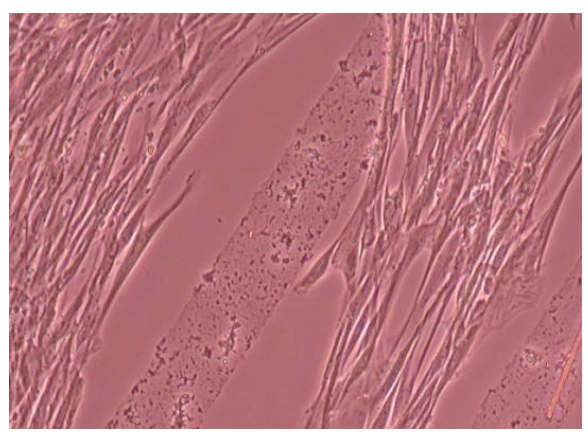

(b)

FIGURE 6: CnC on PDDA micropatterns at 3 days after seeding: (a) (PSS/PDDA) $)_{5}-100 \mu \mathrm{m}$, (b) (PSS/PDDA) ${ }_{10}-100 \mu \mathrm{m}$.

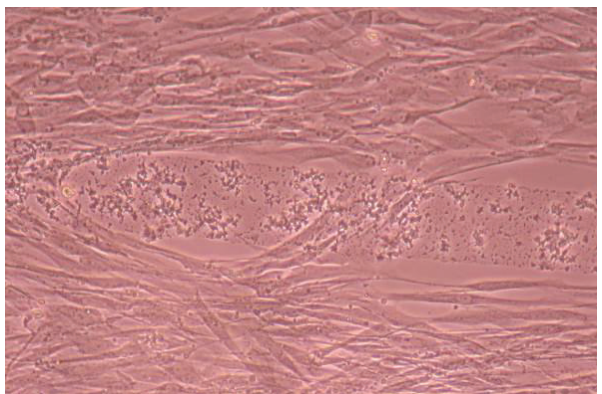

(a)



(b)

Figure 7: CnC on PDDA micropatterns at 10 days after seeding: (a) (PSS/PDDA) $)_{5}-100 \mu \mathrm{m}$, (b) (PSS/PDDA) $10-80 \mu \mathrm{m}$.

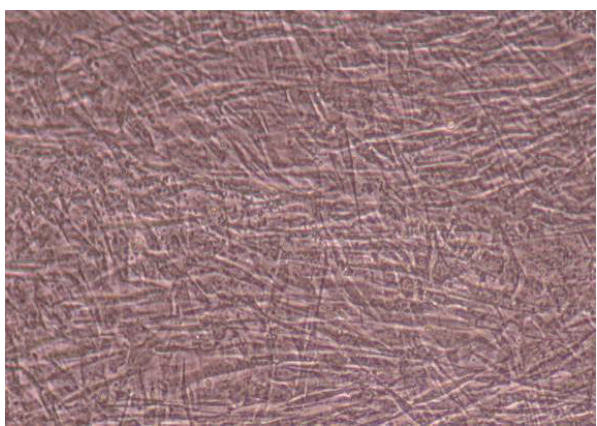

(a)

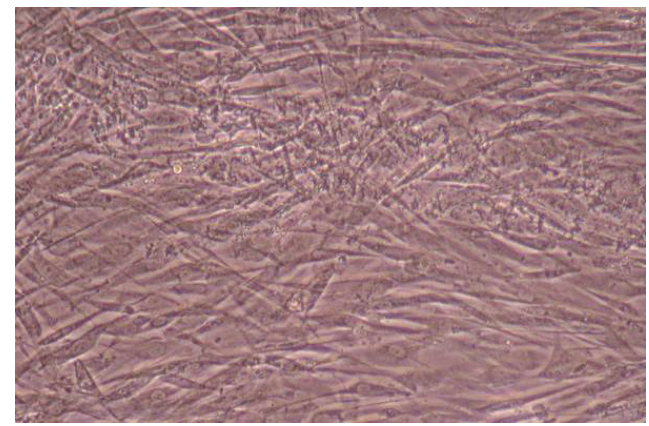

(b)

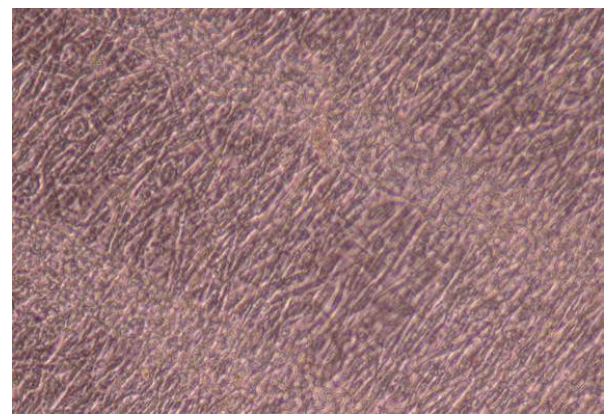

(c)

FIGURE 8: CnC on PDDA micropatterns at 11 days after seeding: (a) (PSS/PDDA) $5-80 \mu \mathrm{m},(\mathrm{b})(\mathrm{PSS} / \mathrm{PDDA})_{5}-100 \mu \mathrm{m}$, and $(\mathrm{c})$ $(\mathrm{PSS} / \mathrm{PDDA})_{10}-80 \mu \mathrm{m}$. 


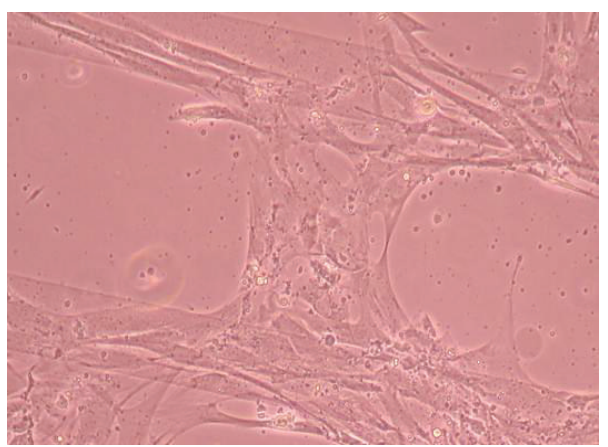

(a)

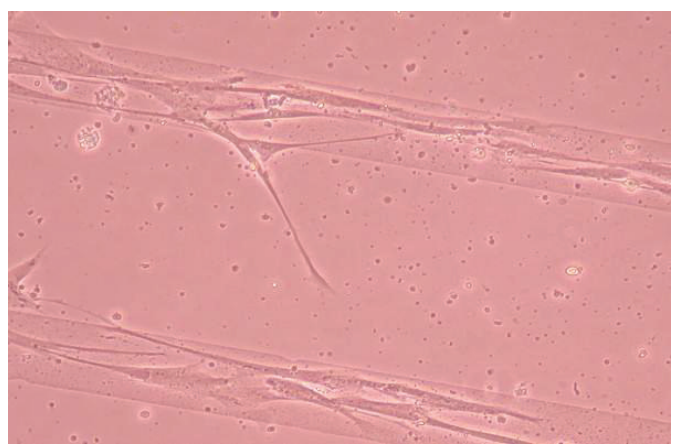

(b)

Figure 9: CnC on PEI micropatterns at 9 days after seeding: (a) (PSS/PEI) ${ }_{10}-100 \mu \mathrm{m}$, (b) (PSS/PEI) $)_{10}-100 \mu \mathrm{m}$.



(a)

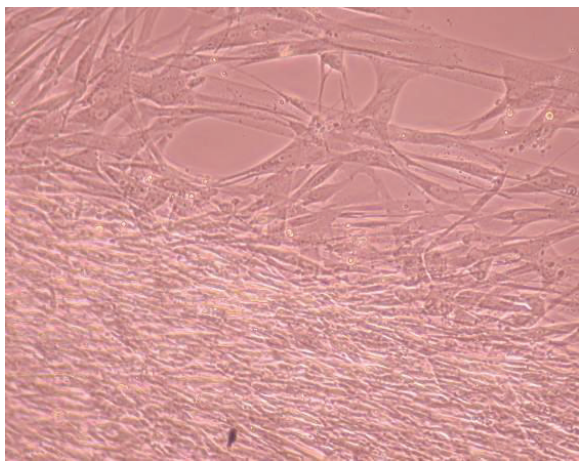

(b)

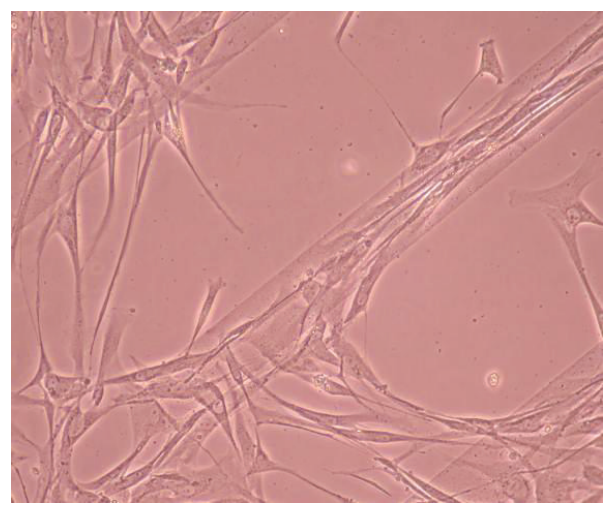

(c)

Figure 10: CnC on PEI micropatterns at 11 days after seeding: (a) (PSS/PEI) $)_{5}-100 \mu \mathrm{m}$, (b) (PSS/PEI $)_{10}-80 \mu \mathrm{m}$, and (c) $(\mathrm{PSS} / \mathrm{PEI})_{10}-100 \mu \mathrm{m}$.

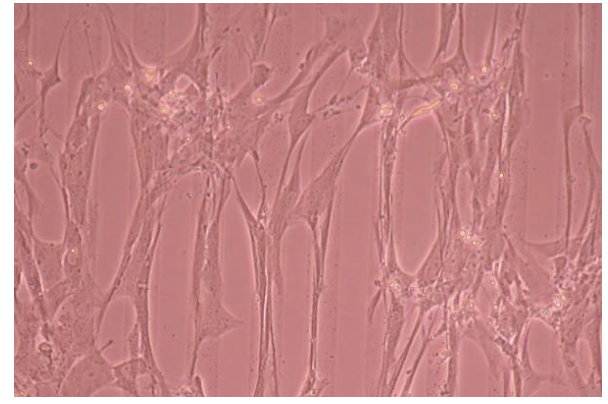

(a)

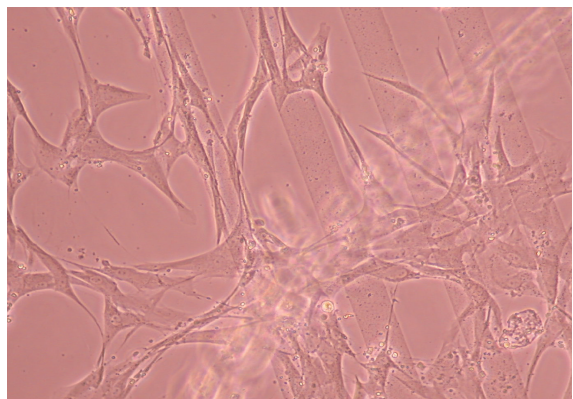

(b)

FIGURE 11: CnC on PSS micropatterns at 9 days after seeding: (a) (PSS/PEI) $)_{4} / \mathrm{PSS}-80 \mu \mathrm{m}$, (b) (PSS/PEI) ${ }_{4} / \mathrm{PSS}-80 \mu \mathrm{m}$. 


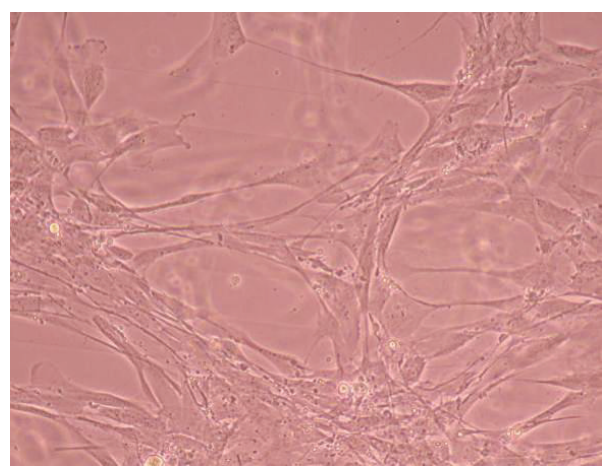

(a)



(b)

FIGURE 12: CnC on PSS micropatterns at 10 days after seeding: (a) (PSS/PEI) ${ }_{4} / \mathrm{PSS}-80 \mu \mathrm{m}$, (b) (PSS/PEI) ${ }_{4} / \mathrm{PSS}-100 \mu \mathrm{m}$.



FIGURE 13: CnC on PSS micropatterns at 11 days after seeding: (PSS/PEI) $)_{4} / \mathrm{PSS}-100 \mu \mathrm{m}$.

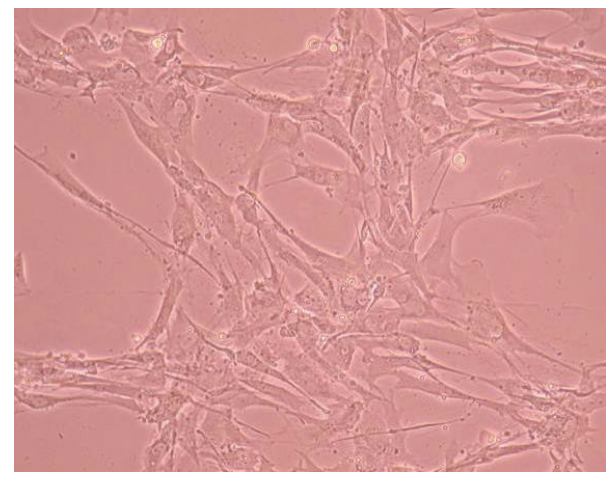

FIGURE 14: $\mathrm{CnC}$ on collagen micropatterns at 10 days after seeding: (PSS/Collagen $)_{5}-100 \mu \mathrm{m}$.

$80 \mu \mathrm{m}$ stripe patterns and $300 \mu \mathrm{m}$ for the $100 \mu \mathrm{m}$ stripe patterns. From Figures 1-5, it is also clear that the 10-bilayer micropatterns appear to have better surface coverage of materials compared to their 5-bilayer counterparts.

3.2. Phase-Contrast Microscopy of $\mathrm{CnC}$ on Micropatterned Substrates. Figures 6, 7, 8, 9, 10, 11, 12, 13, 14, 15, 16, 17, and 18 contain representative phase-contrast images of the

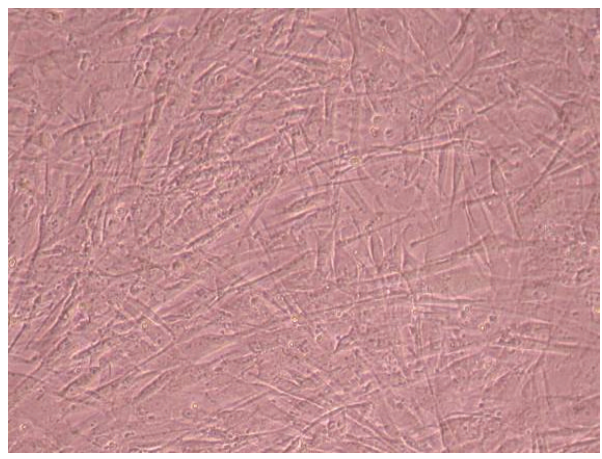

FIGURE 15: $\mathrm{CnC}$ on collagen micropatterns at 11 days after seeding: (PSS/Collagen) $)_{5}$.

chondrocytes on micropatterned substrates of five different materials, in five- and ten-bilayer nanofilm configurations. In all the multilayer nanofilm architectures, the terminating nanofilm layer was one of the five different materials studied here, and the background material is a single layer of PDDA.

Figure 6 shows $\mathrm{CnC}$ on PDDA-terminating substrates 3 days after cell seeding. The cells appear to be avoiding the PDDA stripe patterns and are showing defined growth on the surfaces between the stripe patterns coated with a single nanofilm layer of PDDA. PDDA was shown to be a cytophobic material that inhibited smooth muscle cells and neuronal attachment $[35,37]$. From our AFM measurements [39], it was observed that the thicknesses of 5 and 10 bilayers of PDDA are roughly $59.61 \pm 4.07$ and $251.58 \pm 6.28 \mathrm{~nm}$ (mean \pm standard deviation), respectively. Both these thicknesses are considerably greater than the thickness of a PDDA monolayer. Chondrocytes seem to prefer a thinner PDDA layer for their attachment as compared to the thicker-layered micropatterned PDDA.

From Figure 7 it can be seen that some $\mathrm{CnC}$ are growing on the PDDA micropatterns. However, the growth of $\mathrm{CnC}$ between the micropatterns is still greater than that on the micropatterns, and it is clear that the cells have reached confluence on the PDDA micropatterns (as seen in Figure 8). From Figures 9 and 10, it can be observed that $\mathrm{CnC}$ are preferentially growing on the PEI micropatterns. 


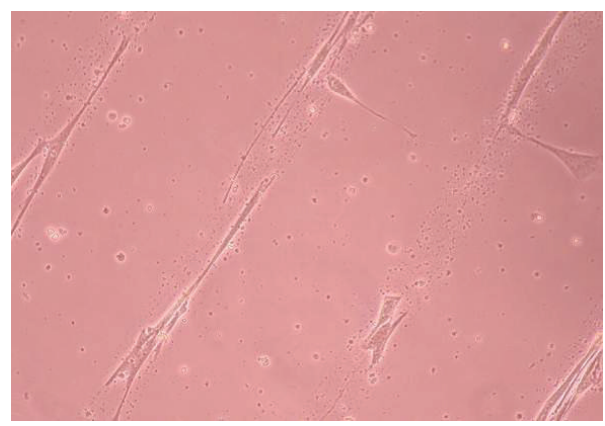

(a)

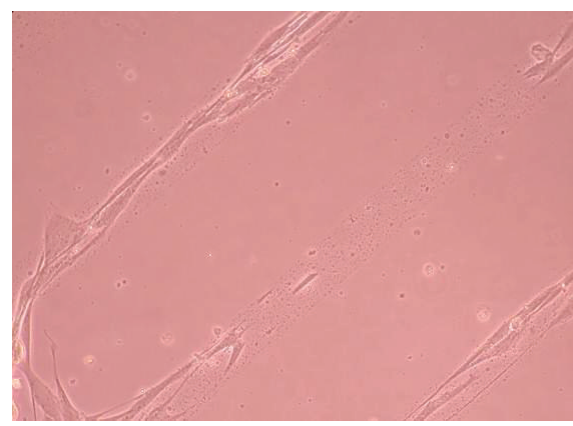

(b)

Figure 16: CnC on CS micropatterns at 9 days after seeding: (a) $(\mathrm{CS} / \mathrm{PEI})_{4} / \mathrm{CS}-80 \mu \mathrm{m}$, (b) $(\mathrm{CS} / \mathrm{PEI})_{9} / \mathrm{CS}-80 \mu \mathrm{m}$.

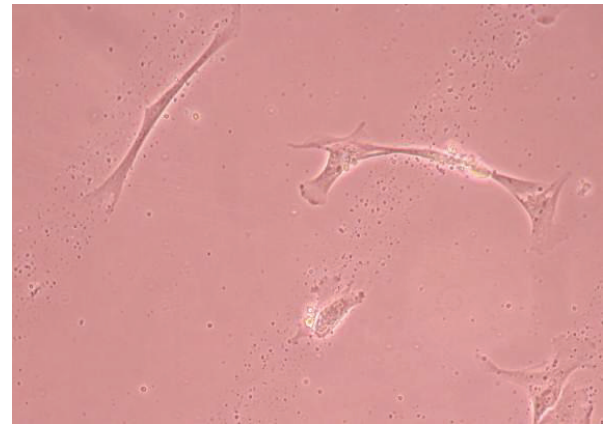

(a)

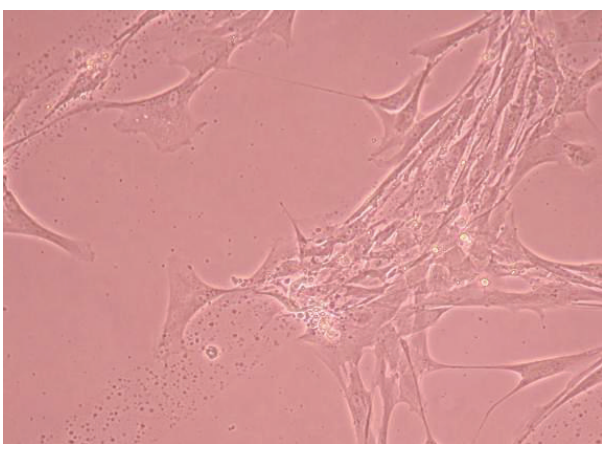

(c)

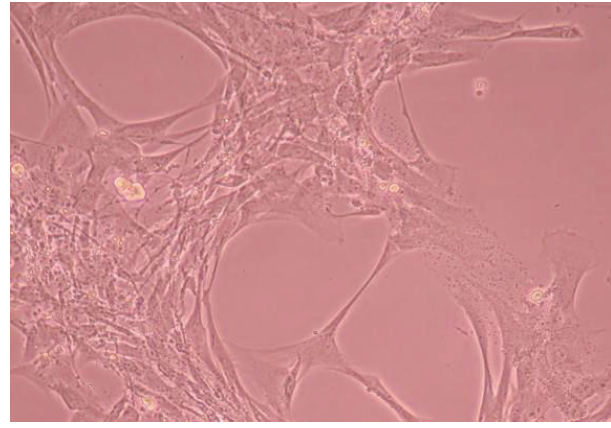

(b)

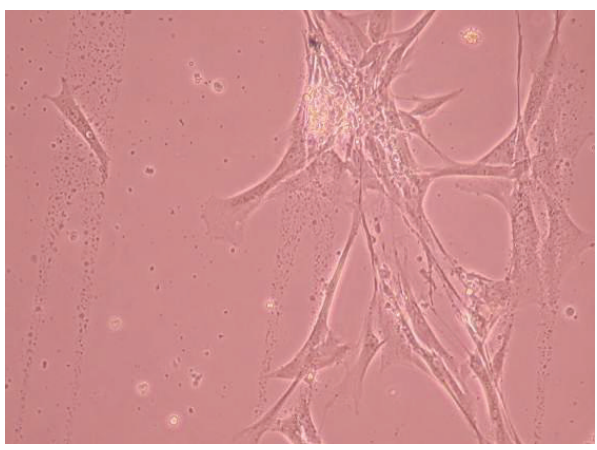

(d)

Figure 17: CnC on CS micropatterns at 10 days after seeding: (a) $(\mathrm{CS} / \mathrm{PEI})_{4} / \mathrm{CS}-80 \mu \mathrm{m},(\mathrm{b})(\mathrm{CS} / \mathrm{PEI})_{4} / \mathrm{CS}-100 \mu \mathrm{m},(\mathrm{c})(\mathrm{CS} / \mathrm{PEI})_{9} / \mathrm{CS}-$ $100 \mu \mathrm{m}$, and (d) $(\mathrm{CS} / \mathrm{PEI})_{9} / \mathrm{CS}-80 \mu \mathrm{m}$.

From Figure 10(b), it is clearly shown that $\mathrm{CnC}$ growing on the micropatterns were aligned along the length of the stripe patterns, whereas $\mathrm{CnC}$ growing on unpatterned substrate are attached and growing on the monolayer of PDDA.

Figures 11-13 demonstrate that $\mathrm{CnC}$ growth is mainly restricted to the PSS micropatterns. The $\mathrm{CnC}$ on the micropatterns were aligned along the length of the stripe patterns. From Figures 14 and 15, $\mathrm{CnC}$ have also grown to confluence. The confluent $\mathrm{CnC}$ make the collagen micropatterns very hard to be discerned in the images. From Figures 16-18, it can be observed that $\mathrm{CnC}$ are preferentially growing on the $\mathrm{CS}$ micropatterns. Also, it can be observed that $\mathrm{CnC}$ growing on the micropatterns are aligned along the length of the stripe patterns.

\section{Discussion}

Several similar studies have been conducted in other eukaryotic cells [11, 14, 24, 35, 40-45], and a few studies have also focused on different types of chondrocytes [46]. Also, diverse methods have been adapted to create the micropatterns required for the studies. To our knowledge, ours is the first study using canine chondrocytes as a model for directed growth on micropatterned substrates. The majority of the above-mentioned studies have reported constrained and preferential cell growth on micropatterned substrates. Specifically, protein micropatterns (bone morphogenetic protein 2 (BMP-2) printed on polystyrene (PS)) fabricated by microcontact printing significantly influenced the adhesion, 


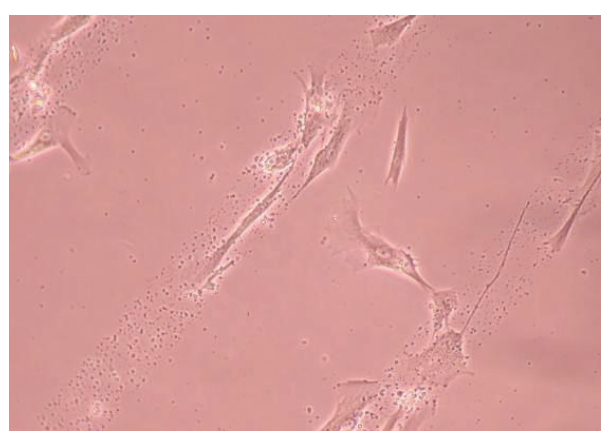

(a)

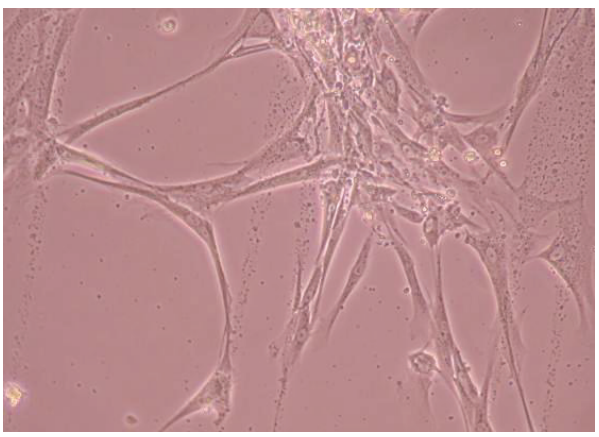

(c)



(b)

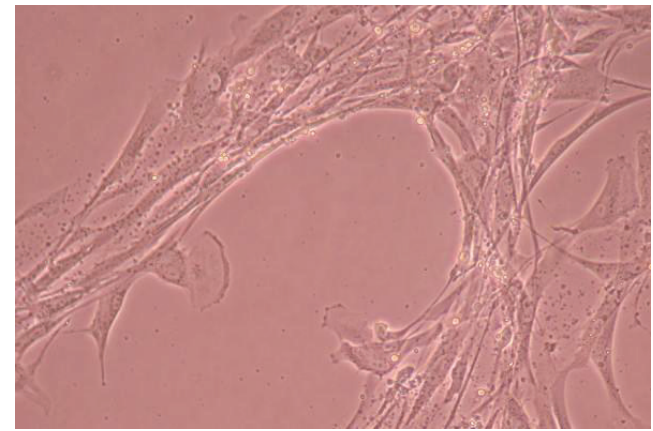

(d)

FIGURE 18: CnC on CS micropatterns at 11 days after seeding: (a) $(\mathrm{CS} / \mathrm{PEI})_{4} / \mathrm{CS}-80 \mu \mathrm{m},(\mathrm{b})(\mathrm{CS} / \mathrm{PEI})_{4} / \mathrm{CS}-100 \mu \mathrm{m},(\mathrm{c})(\mathrm{CS} / \mathrm{PEI})_{9} / \mathrm{CS}-$ $80 \mu \mathrm{m}$, and $(\mathrm{d})(\mathrm{CS} / \mathrm{PEI})_{9} / \mathrm{CS}-100 \mu \mathrm{m}$.

spread, alignment, and functions of human chondrocytes. As in our studies and several similar studies, human chondrocytes showed preferential adhesion on the BMP-2 micropatterns. Both the shapes and sizes of the micropatterns were instrumental in influencing cell adhesion, cell morphology, the degree of spreading of the cells, and more significantly type II and VI collagen expression, thus emphasizing the importance of protein micropatterns in influencing the growth and functionality of human chondrocytes [47].

While our studies were not focused on expression of different collagen and proteoglycan types, future studies will be directed towards analysis of gene expression and protein synthesis including the level of phenotypic protein marker expression as well as the potential for long-term chondrocyte functionality on micropatterned substrates. These studies would be beneficial in understanding the influence of micropatterns generated from proteins and other biomaterials on the growth and behavior of canine chondrocytes. Incorporation of growth factors and other bioactive factors that may modulate the behavior of canine chondroctyes should also be addressed. Micropatterns generated using the LbL-LO technique used in the current study can be helpful in creating in vitro drug-delivery models for studying the effects of different drugs on chondrocytes of varying types (growth versus articular cartilage). Our previous work, current study, and the suggested future studies (short-term and long-term) would also be extremely useful in cartilage tissue engineering and also for creating disease-study models, studying chondrocyte involvement in degenerative changes in articular cartilage, for example.

\section{Conclusions}

Defined and restrained growth of canine chondrocytes was achieved on 5 and 10 bilayer micropatterns fabricated using the LbL-LO technique. From the morphological observations, the 5- and 10-bilayer nanofilms do not produce any apparent differences in the growth pattern of $\mathrm{CnC}$.

$\mathrm{CnC}$ appeared to remain confluent for a longer period of time on the thinner monolayer PDDA surface between the micropatterns compared to $\mathrm{CnC}$ grown on the thicker PDDA micropatterns. This suggests that 5 and 10 bilayers of micropatterned PDDA might act as cell-resistant surfaces; further studies are needed to understand this observation. CnC exhibited preferential attachment on micropatterns of PEI, PSS, collagen, and CS multilayer nanofilms. CnC growth was stable for an extended period of time on micropatterned PEI, PSS, collagen, and CS suggesting their possible use in biomedical applications.

\section{Conflict of Interests}

The authors declare that there is no conflict of interest.

\section{Acknowledgments}

This work was supported by DARPA and NAVY SPAWAR SC N66001-05-1-8903 Grant awarded to Dr. D. K. Mills and by the National Science Foundation (Grant no. 0092001). 


\section{References}

[1] M. Théry, "Micropatterning as a tool to decipher cell morphogenesis and functions," Journal of Cell Science, vol. 123, no. 24, pp. 4201-4213, 2010.

[2] C. S. Chen, M. Mrksich, S. Huang, G. M. Whitesides, and D. E. Ingber, "Micropatterned surfaces for control of cell shape, position, and function," Biotechnology Progress, vol. 14, no. 3, pp. 356-363, 1998.

[3] M. C. Berg, S. Y. Yang, P. T. Hammond, and M. F. Rubner, "Controlling mammalian cell interactions on patterned polyelectrolyte multilayer surfaces," Langmuir, vol. 20, no. 4, pp. 1362-1368, 2004.

[4] S. N. Bhatia, M. L. Yarmush, and M. Toner, "Controlling cell interactions by micropatterning in co-cultures: Hepatocytes and 3T3 fibroblasts," Journalof Biomedical Materials Research, vol. 34, pp. 189-199, 1997.

[5] Y. S. Zinchenko, L. W. Schrum, M. Clemens, and R. N. Coger, "Hepatocyte and Kupffer cells co-cultured on micropatterned surfaces to optimize hepatocyte function," Tissue Engineering, vol. 12, no. 4, pp. 751-761, 2006.

[6] J. Shaikh Mohammed, M. A. DeCoster, and M. J. McShane, "Fabrication of interdigitated micropatterns of self-assembled polymer nanofilms containing cell-adhesive materials," Langmuir, vol. 22, no. 6, pp. 2738-2746, 2006.

[7] R. Singhvi, A. Kumar, G. P. Lopez et al., "Engineering cell shape and function," Science, vol. 264, no. 5159, pp. 696-698, 1994.

[8] C. S. Chen, M. Mrksich, S. Huang, G. M. Whitesides, and D. E. Ingber, "Geometric control of cell life and death," Science, vol. 276, no. 5317, pp. 1425-1428, 1997.

[9] M. Morra and C. Cassinelli, "Cell adhesion micropatterning by plasma treatment of alginate coated surfaces," Plasmas and Polymers, vol. 7, no. 2, pp. 89-101, 2002.

[10] M. Li, D. K. Mills, T. Cui, and M. J. McShane, "Cellular response to gelatin- and fibronectin-coated multilayer polyelectrolyte nanofilms," IEEE Transactions on Nanobioscience, vol. 4, no. 2, pp. 170-179, 2005.

[11] J. Hyun, H. Ma, P. Banerjee, J. Cole, K. Gonsalves, and A. Chilkoti, "Micropatterns of a cell-adhesive peptide on an amphiphilic comb polymer film," Langmuir, vol. 18, no. 8, pp. 2975-2979, 2002.

[12] D. Falconnet, G. Csucs, H. Michelle Grandin, and M. Textor, "Surface engineering approaches to micropattern surfaces for cell-based assays," Biomaterials, vol. 27, no. 16, pp. 3044-3063, 2006.

[13] D. L. Elbert and J. A. Hubbell, "Conjugate addition reactions combined with free-radical cross-linking for the design of materials for tissue engineering," Biomacromolecules, vol. 2, pp. 430-441, 2001.

[14] A. Tourovskaia, T. Barber, B. T. Wickes et al., "Micropatterns of chemisorbed cell adhesion-repellent films using oxygen plasma etching and elastomeric masks," Langmuir, vol. 19, no. 11, pp. 4754-4764, 2003.

[15] S. Y. Yang, J. D. Mendelsohn, and M. F. Rubner, "Patternable, cell-resistant surfaces prepared with H-bonded polyelectrolyte multilayers," Polymer Preprints (American Chemical Society, Division of Polymer Chemistry), vol. 43, pp. 723-724, 2002.

[16] S. Y. Yang, J. D. Mendelsohn, and M. F. Rubner, "New class of ultrathin, highly cell-adhesion-resistant polyelectrolyte multilayers with micropatterning capabilities," Biomacromolecules, vol. 4, no. 4, pp. 987-994, 2003.
[17] M. Morra and C. Cassinelli, "Surface studies on a model cellresistant system," Langmuir, vol. 15, no. 13, pp. 4658-4663, 1999.

[18] H. Ma, J. Hyun, Z. Zhang, T. P. Beebe, and A. Chilkoti, "Fabrication of biofunctionalized quasi-three-dimensional microstructures of a nonfouling comb polymer using soft lithography," Advanced Functional Materials, vol. 15, no. 4, pp. 529-540, 2005.

[19] A. Khademhosseini, S. Jon, K. Y. Suh et al., "Direct patterning of protein- and cell-resistant polymeric monolayers and microstructures," Advanced Materials, vol. 15, no. 23, pp. 19952000, 2003.

[20] S. G. Olenych, M. D. Moussallem, D. S. Salloum, J. B. Schlenoff, and T. C. S. Keller, "Fibronectin and cell attachment to cell and protein resistant polyelectrolyte surfaces," Biomacromolecules, vol. 6, no. 6, pp. 3252-3258, 2005.

[21] A. Tourovskaia, X. Figueroa-Masot, and A. Folch, "Differentiation-on-a-chip: a microfluidic platform for long-term cell culture studies," Lab on a Chip, vol. 5, no. 1, pp. 14-19, 2005.

[22] J. D. Mendelsohn, S. Y. Yang, J. A. Hiller, A. I. Hochbaum, and M. F. Rubner, "Rational design of cytophilic and cytophobic polyelectrolyte multilayer thin films," Biomacromolecules, vol. 4, no. 1, pp. 96-106, 2003.

[23] J. Tan and W. M. Saltzman, "Topographical control of human neutrophil motility on micropatterned materials with various surface chemistry," Biomaterials, vol. 23, no. 15, pp. 3215-3225, 2002.

[24] L. Lu, L. Kam, M. Hasenbein et al., "Retinal pigment epithelial cell function on substrates with chemically micropatterned surfaces," Biomaterials, vol. 20, no. 23-24, pp. 2351-2361, 1999.

[25] J. T. Groves, L. K. Mahal, and C. R. Bertozzi, "Control of cell adhesion and growth with micropatterned supported lipid membranes," Langmuir, vol. 17, no. 17, pp. 5129-5133, 2001.

[26] J. Lahann, M. Balcells, T. Rodon et al., "Reactive polymer coatings: a platform for patterning proteins and mammalian cells onto a broad range of materials," Langmuir, vol. 18, no. 9, pp. 3632-3638, 2002.

[27] E. Ostuni, R. Kane, C. S. Chen, D. E. Ingber, and G. M. Whitesides, "Patterning mammalian cells using elastomeric membranes," Langmuir, vol. 16, no. 20, pp. 7811-7819, 2000.

[28] R. McBeath, D. M. Pirone, C. M. Nelson, K. Bhadriraju, and C. S. Chen, "Cell shape, cytoskeletal tension, and RhoA regulate stem cell lineage commitment," Developmental Cell, vol. 6, no. 4, pp. 483-495, 2004.

[29] L. Gao, R. McBeath, and C. S. Chen, "Stem cell shape regulates a chondrogenic versus myogenic fate through racl and $\mathrm{N}$ cadherin," Stem Cells, vol. 28, no. 3, pp. 564-572, 2010.

[30] J. Shaik, J. S. Mohammed, M. J. McShane, and D. K. Mills, "Growth and behaviour of bovine articular chondrocytes on nanoengineered surfaces: part I," International Journal of Nanotechnology, vol. 8, no. 8-9, pp. 679-699, 2011.

[31] J. Shaik, J. S. Mohammed, M. J. McShane et al., "In vitro evaluation of chondrosarcoma cells and canine chondrocytes on layer-by-layer (LbL) self-assembled multilayer nanofilms," Biofabrication, vol. 5, Article ID 015004, 2013.

[32] J. C. Daniel and D. K. Mills, "Proteoglycan synthesis by cells cultured from regions of the rabbit flexor tendon," Connective Tissue Research, vol. 17, no. 3, pp. 215-230, 1988.

[33] J. Glowacki, E. Trepman, and J. Folkman, "Cell shape and phenotypic expression in chondrocytes," Proceedings of the Society for Experimental Biology and Medicine, vol. 172, no. 1, pp. 93-98, 1983. 
[34] M. Li, K. K. Kondabatni, T. Cui, and M. J. McShane, "Fabrication of 3-D gelatin-patterned glass substrates with layer-by-layer and lift-off (LbL-LO) technology," IEEE Transactions on Nanotechnology, vol. 3, no. 1, pp. 115-123, 2004.

[35] J. S. Mohammed, M. A. DeCoster, and M. J. McShane, "Micropatterning of nanoengineered surfaces to study neuronal cell attachment in vitro," Biomacromolecules, vol. 5, no. 5, pp. 1745-1755, 2004.

[36] J. Shaik and D. K. Mills, "Micropatterned antibody-terminated nanocomposites (MANs) fabricated using layer-by-layer lift-off (LBL-LO) technique," Journal of Biomedical Materials Research $B$, vol. 100, pp. 1411-1415, 2012.

[37] M. Li, T. Cui, D. K. Mills, Y. M. Lvov, and M. J. McShane, "Comparison of selective attachment and growth of smooth muscle cells on gelatin- and fibronectin-coated micropatterns," Journal of Nanoscience and Nanotechnology, vol. 5, no. 11, pp. 1809-1815, 2005.

[38] J. Shaikh Mohammed, Multicomponent patterning of nanocomposite polymer and nanoparticle films using photolithography and layer-by-layer self-assembly [Ph.D. dissertation], Louisiana Tech University, Ruston, La, USA, 2006.

[39] J. Shaik, Growth and behavior of chondrocytes on nano engineered surfaces and construction of micropatterned co-culture platforms using layer-by-layer platforms using layer-by-layer assembly lift-off method [Ph.D. dissertation], Louisiana Tech University, Ruston, La, USA, 2007.

[40] Y. S. Zinchenko and R. N. Coger, "Engineering micropatterned surfaces for the coculture of hepatocytes and Kupffer cells," Journal of Biomedical Materials Research A, vol. 75, no. 1, pp. 242-248, 2005.

[41] J. Shaikh-Mohammed, M. A. DeCoster, and M. J. McShane, "Cell adhesion testing using novel testbeds containing micropatterns of complex nanoengineered multilayer films," in Proceedings of the 26th Annual International Conference of the IEEE Engineering in Medicine and Biology Society (EMBC '04), vol. 4, pp. 2671-2674, September 2004.

[42] H. Ma, D. Li, X. Sheng, B. Zhao, and A. Chilkoti, "Proteinresistant polymer coatings on silicon oxide by surface-initiated atom transfer radical polymerization," Langmuir, vol. 22, no. 8, pp. 3751-3756, 2006.

[43] L. Lu, K. Nyalakonda, L. Kam, R. Bizios, A. Göpferich, and A. G. Mikos, "Retinal pigment epithelial cell adhesion on novel micropatterned surfaces fabricated from synthetic biodegradable polymers," Biomaterials, vol. 22, no. 3, pp. 291-297, 2001.

[44] J. Y. Lee, C. Jones, M. A. Zern, and A. Revzin, "Analysis of local tissue-specific gene expression in cellular micropatterns," Analytical Chemistry, vol. 78, no. 24, pp. 8305-8312, 2006.

[45] A. Khademhosseini, K. Y. Suh, J. M. Yang et al., "Layer-by-layer deposition of hyaluronic acid and poly-L-lysine for patterned cell co-cultures," Biomaterials, vol. 25, no. 17, pp. 3583-3592, 2004.

[46] N. A. Bullett, D. P. Bullett, F. E. Truica-Marasescu, S. Lerouge, F. Mwale, and M. R. Wertheimer, "Polymer surface micropatterning by plasma and VUV-photochemical modification for controlled cell culture," Applied Surface Science, vol. 235, no. 4, pp. 395-405, 2004.

[47] C. J. Pan, Y. X. Dong, Y. D. Nie, and Y. L. Wang, "Effects of protein micropatterns of biomaterials surfaces on human chondrocytes morphology and protein expression," Progress in Biochemistry and Biophysics, vol. 37, no. 12, pp. 1296-1302, 2010. 

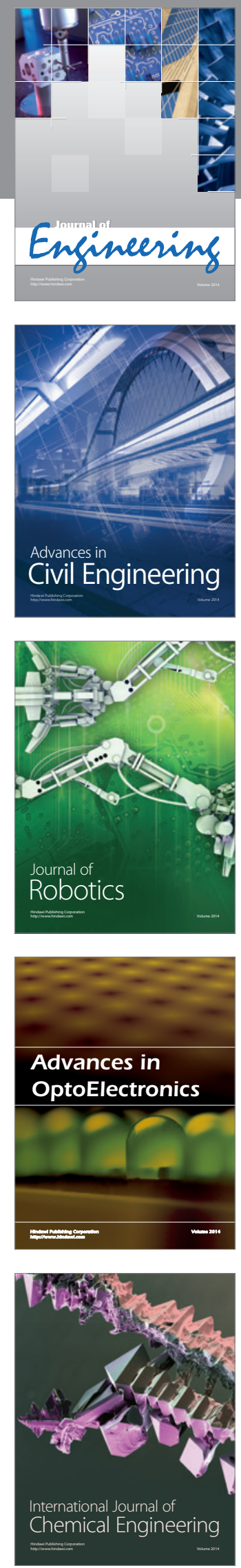

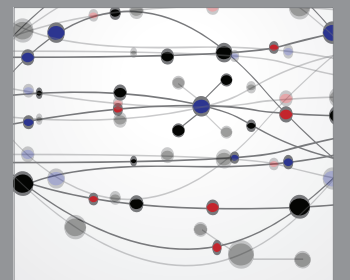

The Scientific World Journal
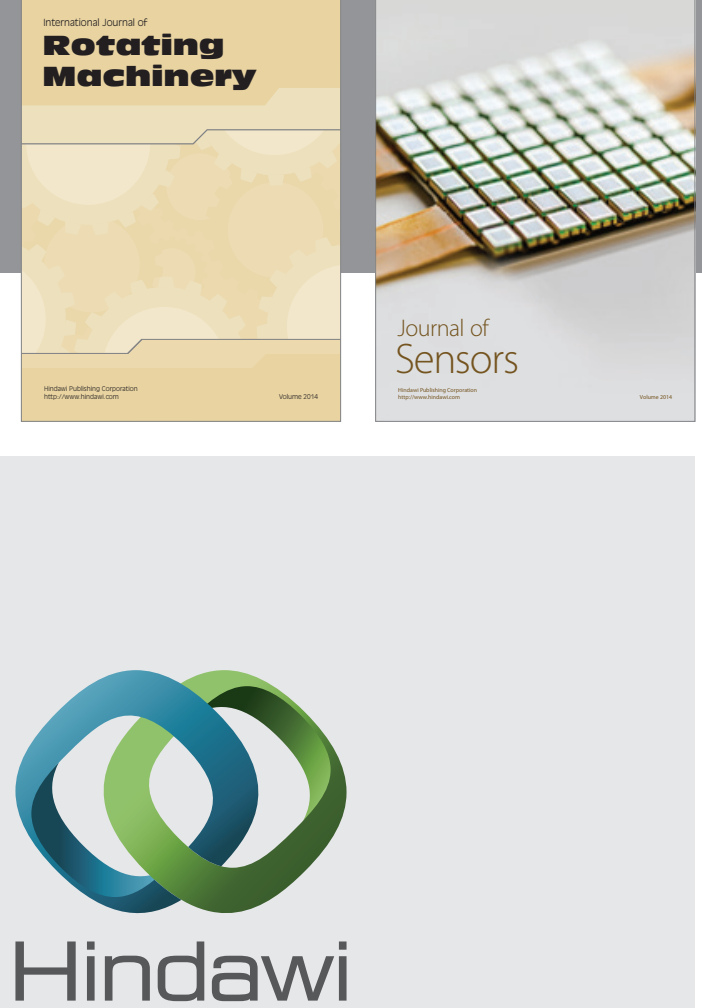

Submit your manuscripts at http://www.hindawi.com
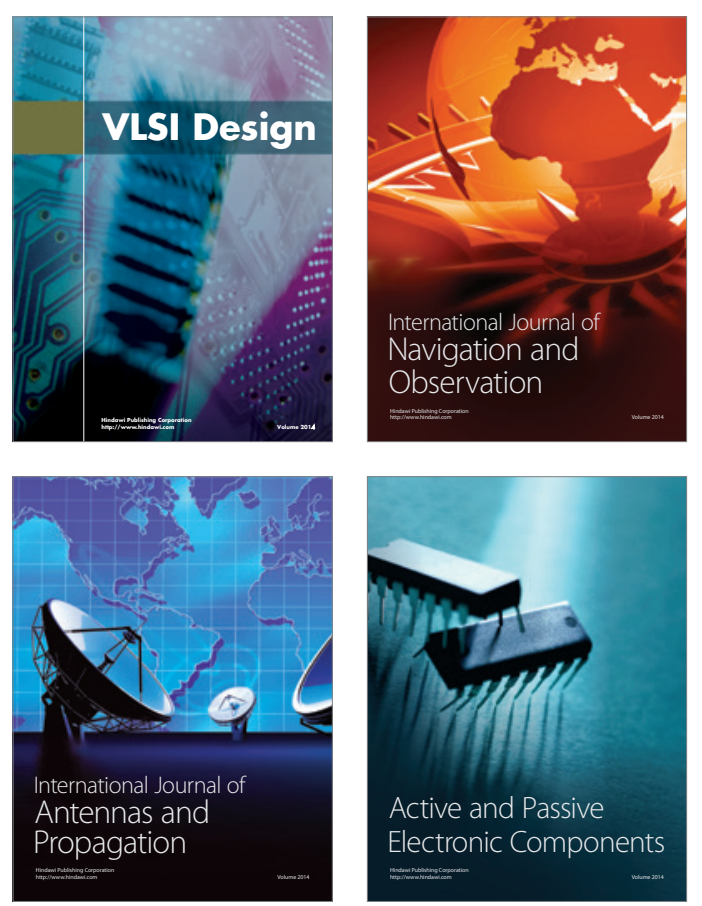


Journal of

Control Science

and Engineering
